\title{
Building a Framework to Support Project-Based Collaborative Learning Experiences in an Asynchronous Learning Network
}

\author{
Timothy J. Ellis and William Hafner \\ Nova Southeastern University \\ Graduate School of Computer and Information Sciences \\ Fort Lauderdale, Florida, USA
}

ellist@nova.edu, hafnerw@nova.edu

\begin{abstract}
Providing students in an asynchronous learning network (ALN) a rich learning environment is not easy, especially in terms of promoting higher cognitive functioning such as analysis and evaluation. The use of project-based, collaborative assignments has been demonstrated to foster greater depth of learning in traditional classroom settings, but this type of assignment is very difficult to plan, develop, and execute in an ALN. This paper presents a case study describing a systemsbased framework for designing, implementing, and evaluating project-based collaborative learning experiences to be delivered via an ALN. Included in the framework is an analysis of the benefits of both collaborative and project-based learning, an examination of the challenges to incorporating project-based collaborative learning activities, and an examination of specific procedures to address those challenges.
\end{abstract}

Keywords: project-based learning, collaborative learning, distance education, asynchronous learning networks.

\section{Introduction}

Providing educational services via an asynchronous learning network (ALN) is fraught with a great number of challenges, especially when concerned with the higher cognitive levels such as analysis and evaluation. The use of project-based, collaborative assignments has been demonstrated to foster greater depth of learning in traditional classroom settings, but this type of assignment is very difficult to plan, develop, and execute in an ALN. The goal of this paper is to present a case study of a framework for designing and implementing project-based collaborative assignments that has been developed and documented over the course of the past five years (Ellis \& Hafner, 2005, 2006, 2007; Hafner \& Ellis, 2004)

Material published as part of this publication, either on-line or in print, is copyrighted by the Informing Science Institute. Permission to make digital or paper copy of part or all of these works for personal or classroom use is granted without fee provided that the copies are not made or distributed for profit or commercial advantage AND that copies 1) bear this notice in full and 2) give the full citation on the first page. It is permissible to abstract these works so long as credit is given. To copy in all other cases or to republish or to post on a server or to redistribute to lists requires specific permission and payment of a fee. Contact Publisher@InformingScience.org to request redistribution permission.
This paper is organized into five major sections. The balance of this introductory section includes an articulation of the problem driving this research and the goals for the study. The second section presents an analysis of the benefits of both collaborative and project-based learning. The third section examines the challenges of incorporating projectbased collaborative learning activities, 
and the fourth section examines the specifics of the framework established to meet those challenges. The final section presents conclusions and a discussion of areas warranting additional research.

\section{Problem Statement}

The value of collaborative work as a tool to promote learning is well-established (Benbunan-Fitch \& Hiltz, 1998; Dillenbourg, Baker, Blaye, \& O’Malley, 1996). Morgan, Whorton, and Gunsalus (2000) established that students engaged in team-based efforts have been shown to become more actively engaged in the learning activity and, consequently, more likely to retain the information being learned longer. Sloffer, Dueber, and Duffy (1999) and Johnson and Johnson (1996) demonstrated that team activities foster higher-order thinking skills such as analytical reasoning, synthesis of multiple information streams into a whole that is indeed greater than the sum of its parts, and evaluation. Students are introduced to an environment that better prepares them to meet the challenges inherent in succeeding in the workforce by more closely paralleling life experiences (McLoughlin \& Luca, 2002; Romano \& Nunamaker, 1998).

Promoting collaboration within a classroom setting is not easy; there is, in fact, often resistance from both the instructor and the student. Many teachers are uncomfortable with collaborative learning assignments, perhaps because they had never worked in the environment as either a student or instructor, and have little understanding of just what types of learning outcomes could be facilitated in a collaborative environment (Muir \& Tracy, 1999). Students, likewise, are often uncomfortable with collaborative learning activities. Those who have been successful in the more traditional, lecture-based environment frequently view collaborative assignments as a threat to their performance and, ultimately, their grade. Many students lack the social skills that are prerequisite to success in collaborative activities and, even for those who are socially adept, adapting to the new expectations and roles fostered by the environment can be threatening (Herreid, 1998).

The problems associated with promoting a collaborative learning experience become magnified exponentially when the course material is delivered via an ALN. The freedom from time and place constraints that attract many students to Web-based courses comes at a significant cost. In an ALN, the absence of the traditional non-verbal queues such as tone of voice and body language and the lack of immediacy in responses can present significant challenges to the establishment of an effective project team. As a result, educators are faced with a dilemma: both students and academic institutions are flocking towards courses offered via an asynchronous learning net-

work, but collaboration, one of the most promising pedagogical tools, appears to be quite difficult in that environment.

Although asynchronous online environments certainly lack the intimacy and immediacy inherent in face-to-face settings and simulated to an extent by synchronous applications, Benbunan-Fitch and Hiltz (1998) established that meaningful collaborative assignments are still possible. Although tools such as threaded discussion boards, email, and dedicated systems have been developed to promote asynchronous collaborative activities, the instructor is still faced with unanswered questions regarding how to plan, develop, and evaluate project-based team activities and effectively weave them into the fabric of the course.

\section{Goals}

The simple availability of tools that can promote collaborative learning is necessary but not in itself sufficient. Before meaningful collaborative assignments can be incorporated in courses delivered via an ALN, the instructor must know how to effectively use those tools in the design of the course (Gagne, Briggs, \& Wagner, 1992). The goal of this study was to develop and test a 
model for planning effective project-based, collaborative assignments for delivery via an asynchronous learning network. Included in the definition of "effective" are:

1. Facilitating the attainment of the learning outcome for which the assignment was designed.

2. Providing the instructor with a means to monitor and evaluate team-based assignments.

3. Alleviating student anxiety regarding team-based assignments.

\section{Why Project Based Collaborative Learning (PBCL)}

The term and concept "learning" does not have a universally accepted definition. Some, for example, describe learning based on the nature of the student's cognitive engagement (Bloom, 1994; Bloom, Engelhart, Furst, Hill, \& Krathwohl, 1956; Gagne et al., 1992) Other learning theoreticians emphasize the type of activity in which the learner engages (Smock, 1981; Zimmerman, 1981), while others focus on the learner's preferred approach to the task (McCarthy, 1991; Riding \& Grimley, 1999). For the purposes of this discussion, Mezirow's (1991) classification of learning across three dimensions of reflection - content, process, and premise - is both appropriate and instructive.

Content level reflection entails acquiring facts and building skills. This level of learning in, for example, a graduate course in multimedia systems, would include topics such as discussing the characteristics of various graphic file formats and video CODECs, and developing skills such as using authoring software to create a product that incorporates voice-over narration and streaming video. Didactic instruction supported by texts, guided laboratory sessions, and modeling has proven effective for promoting learning at the content reflection level.

Process level reflection entails developing problem solving ability. Learning at the process level of reflection in the multimedia systems course would include selecting the appropriate graphic file format or video CODEC to use in a given application. Inherent in that selection process would be an understanding of the strengths and weaknesses of each alternative and an in-depth appreciation of the requirements for the application.

Premise level reflection, the most cognitively demanding learning, entails an analysis and evaluation of the value and relevance of the subject matter. In the multimedia systems course, knowing when and why to use, or not use, voice over narration or streaming video - or any media enhancement at all - would be inherent in learning at the premise level of reflection.

The tools for promoting learning at the process and premise levels of reflection are neither clearly identified nor universally accepted; the specific tools to develop the necessary critical thinking and problem solving capabilities are not, unfortunately, easily identified. Walker (2000) identified some general goals for learning within this level of reflection, including organizing knowledge, building upon prior experiences, developing problem-solving strategies, and engaging in hindsight analysis.

Constructivism is a widely accepted learning theory that offers significant insight into the means of facilitating the development of the problem solving capacities inherent in process level reflection. Constructivism, as described by Niederhauser, Salem, and Fields (1999), is a learnercentered approach that emphasizes the importance of the active involvement of the student in the building of knowledge by integrating new information with her or his existing experiences.

The theory underlying constructivism as articulated by Vygotsky (1986) focuses more on the environment in which learning can occur than on any particular pedagogical technique. It is vital to create a context in which learning can occur (Hill, 1999). For many college-level courses, that context often is problem-centered and activity-based. Multiple tools and resources that the learner 
can manipulate and use for exploration are important, as is support for reflection and selfassessment. In effect, the environment should provide a firm foundation for scaffolding learning through coaching, modeling, and a forum for sharing problem solving strategies.

The ability to accurately assess value and relevance is typically developed only over time and as a result of life experiences. This type of longitudinal learning is usually promoted through collaborative projects. The value of collaboration as a tool to promote rich learning opportunities is well recognized (Collins-Eaglin \& Karabenick, 1997; Daggs, Styres, \& Turner, 1997; Morgan et al., 2000) as is the importance of reality-based projects (Hakkarainen et al., 2001). Collaborative enquiry-based learning experiences such as WebQuests have been shown to promote greater cognitive presence (Kanuka, Rourke, \& Laflamme, 2007) and higher-order learning in the form of increased ability to analyze, synthesize, and evaluate knowledge among both college students (Alan $\&$ Street, 2007) and children (Ikpeze \& Boyd, 2007).

\section{Challenges to Implementing PBCL Assignments}

Although, as detailed above in the Problem Statement section, there are a number attitudinal issues that make incorporation of PBCL assignments in an ALN difficult, there are two very pragmatic questions that must be answered at the design level for this type of assignment: how can the teams be structured (Ellis \& Hafner, 2007) and how can the work done within the team be evaluated (Ellis \& Hafner, 2005). The next two sections examine these questions by exploring control structures in the PBCL and assessment of team work.

\section{Control Structure and the PBCL}

Within any project team there are identifiable roles and task-specific duties that must be fulfilled for that project (Vaughan, 2004). Control structure refers to the manner in which responsibility for executing the tasks associated with each role is assigned. Control structure within a PBCL assignment can vary on a continuum from an entirely democratic model in which students are allowed to develop their own control structure to an autocratic model in which students are assigned by the instructor to specific roles and associated responsibilities.

Research has indicated that the autocratic model offers noteworthy pedagogical value. Johnson and Johnson, (1996) and Ellis and Hafner (2007) compared performance and satisfaction of students participating in structured information systems team environments with that of students who were allowed to determine their own roles and responsibilities. The students in the more autocratically structured teams recorded statistically significant better performance and greater satisfaction with the group experience than those participating in teams based on a more democratic structure. The autocratic model also seems to better reflect the reality of the workplace where there usually are clear distinctions among job categories and responsibilities. Educationally, the autocratic model appears to provide the necessary scaffolding upon which the desired learning experience can be built (Smock, 1981; Zimmerman, 1981).

Despite the evidence and arguments supporting the autocratic model, there are equally compelling reasons to implement PBCL assignments in a more democratic fashion. At a very functional level, the democratic model more closely parallels the actual power structure within a team that, essentially, is collaboration among peers. The democratic structure also promotes a greater sense of ownership of the process and products than when the structure is imposed by an outside authority (Guttman, 2004; Orsburn, Moran, Musselwhite, \& Zenger, 1990; Thompson, Baughan, \& Motwani, 1998). Finally, the democratic model is more in harmony with essence of studentdirectedness inherent in the theoretical foundation upon which project-based learning is built (Moursund, 2003; Thomas, 2000). 


\section{Assessment}

It is clearly not adequate to evaluate a collaborative, project-based assignment by merely rating the artifacts produced. "If our courses have the objective of developing students' capacity to work as part of a team, then we need some means of assessing teamwork in a fair and meaningful way ..." (Freeman \& McKenzie, 2002, p. 552). The literature contains a number of both general suggestions and specific rubrics for that "fair and meaningful" evaluation.

In general, it is vital to clarify the purpose of the assessment - to measure student learning or group productivity - and ensure that the design of the evaluation is consistent with that purpose (Webb, 1997). It is also of value to conduct an evaluation early in the collaborative experience and repeat the process at least once before the end of the exercise (Brooks \& Ammons, 2003). The structure of the evaluation instrument is likewise important. The rating criteria must be clearly defined and expressed in terms that promote an evaluation of past performance, not expected behavior (Falchikov \& Goldfinch, 2000; Van Duzer \& McMartin, 2000).

Although an effective, detailed, general-purpose rubric for conducting peer assessments has not been developed - and, given the very large number of variables in class structure and goals for the collaborative learning experience, may not be feasible - a number of templates for the peer assessment rubric have been proposed (Brooks \& Ammons, 2003; Freeman \& McKenzie, 2002; Goldfinch, 1994; Van Duzer \& McMartin, 2000). Likert-scales containing between four and eight degrees of granularity are commonly used to rate two aspects of the group experience: the functioning of the group as a whole, and the performance of each individual member. Examples of the first type of rating include:

- "Did all members of the group share in the team's responsibilities?" (Van Duzer \& McMartin, 2000, p. 156)

- “How productive was the group overall?" (Van Duzer \& McMartin, 2000, p. 156)

Examples of questions rating individual performance include:

- "Prompt in attendance at team meetings." (Brooks \& Ammons, 2003, p. 270.)

- "Suggesting ideas" (Freeman \& McKenzie, 2002, p. 557)

- "Kept an open mind/was willing to consider other's ideas" (Van Duzer \& McMartin, 2000, p. 156)

Although there is a great deal of guidance from the literature regarding what questions could form a fair and meaningful peer evaluation instrument, a vital question remains unaddressed: Upon what data can the student base her or his evaluation? For example, what can the peer-evaluator examine to determine if colleague " $A$ " deserves a rating of 4 or 3 on the "suggesting ideas" criterion? In a face-to-face collaborative environment, the student has little more than her or his general impressions from the series of group encounters to base a rating. An asynchronous collaborative environment that uses threaded discussion forums to support group interaction (Hafner \& Ellis, 2004) actually offers a potentially richer dataset upon which students can base peer evaluations.

A great deal of research has focused on developing models for analyzing the communication patterns in asynchronous computer conferences. Detailed content analysis models that incorporated elements from discourse theory, cognitive theory, and interaction theory have been developed and tested (Garrison, Anderson, \& Archer, 2000, 2001; Henri, 1982). Rubrics for assessing the interaction present in a course delivered via an ALN have likewise been the subject of considerable research (Roblyer \& Wiencke, 2003; Schrire, 2003). 
The most commonly identified criteria for evaluating participation within threaded discussion forums include level of interaction in the forum: "learner-learner, learner-content, instructorlearner interactivity" (Moore, 1989), degree of presence (Garrison et al., 2000, 2001), and lurking (Beaudoin, 2002) or vicarious interaction (Fulford \& Zhang, 1993). A large number of additional criteria for rating forum participation - timing and pace, providing transitions, facilitating interaction, sharing resources, and promoting group process - are explicitly identified or implied throughout the literature.

The literature likewise contains a number of studies that suggest methods for assessing forum participation in terms of the criteria listed above. A number of rubrics for categorizing contributions have been explored. Level of discourse - i.e. high level discussions, progressive discussions, and low-level discussions (Jarvela \& Hakkinen, 2003) - amount of interaction (Wentling \& Johnson, 1999), indication of critical thinking skills and practical inquiry transactions (Garrison et al., 2000, 2001), and interval "wait" time between a posting and follow-up (Cazden \& Beck, 2003) are among the most interesting and germane categorization rubrics for this discussion.

\section{A PBCL Framework}

To address the challenges of incorporating PBCL activities in a course delivered via an ALN, a five-step model for planning, developing, and evaluating such assignments was developed and tested in a series of graduate level courses in multimedia systems and database systems. The steps are summarized in the following discussion, supplemented by relevant artifacts from one of the multimedia systems courses used as the pilot study for this project.

\section{Step 1: Develop Learning Outcomes}

The planning process for any course must start with identifying learning outcomes. In order for collaborative learning activities to be meaningful, they must be associated with one or more appropriate learning outcomes. Examples of learning outcomes necessitating collaborative activities for the multimedia systems course include: 1) Collaboratively develop a project schedule, requirements document, navigation map, and storyboards to document a well-integrated, mediaenhanced product; 2) Collectively produce the media-enhanced product. Figure 1 lists the learning outcomes developed for the multimedia systems class; item 2, in specific, focuses on the project-based group assignment.

By the end of the course, the student will be able to:

1. Plan, develop, and document a professional-grade multimedia product that can be used to educate, sell, or inform.

2. Work effectively as a member of a multimedia production team.
a. Collaboratively develop a requirements document
b. Collaboratively develop a production schedule
c. Collaboratively develop a navigation map (system flowchart)
d. Collaboratively develop storyboards
e. Collectively produce a well-integrated, media-enhanced product

3. Identify and analyze the technological impediments to multimedia production and distribution.

4. Identify and discuss the technology underlying multimedia objects such as sound files, video files, and graphic files.

5. Identify and analyze the strengths and weaknesses of multimedia-enhanced products.

6. Evaluate and critique multimedia productions.

7. Analyze the current status of multimedia production and distribution systems and predict future advances and implementations.

Figure 1: Sample Learning Outcomes 


\section{Step 2: Match Assignments to Learning Outcomes}

Again, as with any course, assignments must be designed to promote attainment of learning outcomes. For the multimedia systems course, five assignment deliverables were indicated: a media enhanced product, and four associated planning documents - project schedule, requirements document, navigation map, and storyboards. Figure 2 details the specifics of the project-based, team assignment.

\section{Group Multimedia Project}

1. A total of 90 points ( $45 \%$ of course grade) can be earned in this assignment.

2. The assignment will be completed by groups consisting of 3 to 4 students

a. Groups will be organized during the third week of the term

b. Each will have the following four (4) functions:

- Project manager

- Multimedia author

- Designer

- Subject matter expert (In the case of 3-member groups, this role will be divided among all members)

3. Refer to the Group Mechanics outline for an overview of roles, responsibilities, policies, and procedures.

4. You may develop your product using any authoring system you desire, including html, ToolBook, Visual Basic, PowerPoint, or Director.

5. One of the biggest challenges in developing multimedia products lies in problems with distribution. Often, products that work perfectly on the machine on which they were developed fail to run or perform erratically on other computers. You are responsible for developing products that are distributionready. For the purposes of this course, distribution-ready means submitted as a Web page.

- The page must be loaded either on your server or on a special server available at the university.

- If you do not have access to a Web server let the instructor know and directions will be given for accessing the server available for this class at the university.

- Note: do not use your university account: the size of a multimedia product would exceed your memory allocation.

6. Your project should have a running length of approximately four (4) minutes, must be interactive, and must effectively incorporate at least three of the following elements: graphics, animations, pictures, sounds, or videos.

7. The topic of your project is open.

8. Your project may take the form of a training module, an advertising piece, or a marketing piece, delivered as a Web site.

9. As detailed in the Group Mechanics outline, you must submit the following deliverables via ESET the course delivery system

○ The url for your media-enriched Web site

- Project schedule (Project manager only)

- Navigation map (Author only)

- Storyboards for each scene or screen (Designer only)

- Requirements document (Subject matter expert)

$\circ \quad$ Individual Collaboration Reflection (described below)

\section{Collaboration Reflection}

1. This assignment is actually a component of the Group Multimedia Project (see Group Mechanics)

2. During the last week of the term you will be given a link to a questionnaire that will need to complete for this assignment.

3. The questionnaire will be in the form of a Web form. 


\section{Step 3: Determine Control Structure}

As discussed above in the Control Structure and the PBCL section, the literature indicates that the more highly structured, "autocratic" model is more likely to produce a positive learning experience for the student than the unstructured, demographic PBCL (Ellis \& Hafner, 2007; Johnson \& Johnson, 1996). If the more highly structured approach is selected, it is important to identify the appropriate team composition, including the number of participants, the appropriate roles, and both the role-specific and shared responsibilities. For the multimedia systems course, four roles were indicated for the collaborative assignment: project manager, author, designer, and subject matter expert. Figure 3 details the specifics for each of the roles identified and the shared responsibilities by all team members.

\section{Step 4: Establish Communication Pathways}

The nature of the communication pathways is directly related to the assignment structure. The collaborative project entailed five deliverables: requirements document, project schedule, navigation map, storyboards, and the final, media-enhanced product. Six discussion threads - one per deliverable, plus a general communication thread - for each team were indicated. Although students were not prohibited from using synchronous communications tools (chat sessions, conference calls, etc.) or other asynchronous instruments (email), they were strongly encouraged, through the evaluation criteria discussed below, to focus their communication in the threaded discussion forums established for each team.

\section{Step 5: Evaluation}

One of the biggest concerns regarding collaborative activities for both students and teachers is evaluation. Even in face-to-face settings it is difficult to identify and appropriately address problems such as "freeloaders" and "dictators" in a group. In an unconstrained setting such as an asynchronous learning network, in which students are separated by both time and place and the instructor has only indirect contact, fair and accurate evaluation is indeed troublesome. To address this concern, the evaluation of the collaborative assignment included both group and individual factors. Figure 4 details the criteria used for student evaluation in the multimedia systems course.

The grading criteria establish only the framework for the evaluation; unanswered is how that framework can be operationalized in terms of what data can be used for the evaluation and how can those data be collected. This operationalization is especially difficult for the peer- and selfevaluation that is inherent in the Collaboration Reflection. The Appendix presents the data collection rubric used in support of the Collaboration Reflection. 
Roles and Responsibilities

1. Project Manager

a. Overall responsibility for the quality and timeliness of product development

b. Manages development lifecycle, setting a timeline and enforcing due-dates

c. Coordinates interaction among group members

d. Coordinates the efforts of the team, to develop, publish, and maintain the project schedule.

e. Posts the preliminary version of the project schedule.

f. Posts updated versions of the project schedule in the appropriate thread of the team's discussion forum area as necessary

g. Submits the final version of the project schedule, updated to reflect the actual product development.

2. Author

a. Assembles the multimedia product using an authoring system

b. Coordinates the efforts of the team to develop, publish, and maintain product navigation map

c. Produces the product in finished, distribution-ready form

d. Posts the preliminary version of the navigation map .

e. Posts updated versions of the navigation map in the appropriate thread of the team's discussion forum area as necessary

f. Submits the final version of the navigation map.

3. Designer

a. Designs the products screen layout and user interface

b. Responsible for screen for quality and appropriateness all media elements located or developed for the product

c. Coordinates the efforts of the team to develop, publish, and maintain the storyboards for each scene/screen.

d. Posts the preliminary version of all storyboards.

e. Posts updated versions of the storyboards in the appropriate thread of the team's discussion forum area as necessary

f. Submits the final version of the storyboards

4. Subject Matter Expert

a. Ensures the accuracy and completeness of the content of the project

b. Responsible for ensuring against copyright infringement

c. Provides the Designer with a screen-by-screen or scene-by-scene description of the project

d. Coordinates the efforts of the team to develop, publish, and maintain the requirements document

e. Posts the preliminary version of all requirements document.

f. Posts updated versions of the requirements document in the appropriate thread of the team's discussion forum area as necessary

g. Submits the final version of the requirements document.

5. Shared responsibilities

a. The team as a whole is responsible for developing all four documents: project schedule, navigation map, storyboards, and requirements document.

b. Identification of the topic for the media-enhanced product

c. Analysis of the problem that the multimedia-enhanced product will address

d. Overall design of the product, including the type of flow

e. "Look and feel" of the product

f. Types of media elements to be included

g. Locating or creating the necessary media elements such as pictures, graphics, audio files, or videos necessary for the product

Figure 3: Roles \& Responsibilities 


\section{Grading Criteria}

1. Each student will be evaluated on the basis of the work of the team as a whole $(55 \%$ of assignment grade)

a. The team as a whole will be evaluated on the basis of the quality of the final product produced

b. Included in the assessment of the final product will be:

i. Quality of media elements

ii. Effective integration of media elements

iii. Effective interactivity

iv. Synthesis of media elements to improve communication

2. Each student will also be evaluated on her or his individual work as a member of the team, including:

a. Performance in assigned role as shown by the item of documentation for which she or he was responsible (15\% of assignment grade)

i. Project Manager: project schedule

ii. Author: navigation map

iii. Designer: storyboards

iv. Subject Matter Expert: requirements document

b. The Collaboration Reflection ( $15 \%$ of assignment grade)

i. Analyze the contributions each member of the team (including yourself) made to the team effort

ii. Be sure to support your evaluation ratings with data.

I. Please note, your data might well be both quantitative and qualitative.

II. Be sure to present and analyze each type of data in a manner consistent with reporting the results of scholarly research

iii. Assess the overall value of the group experience

c. The instructor's assessment of the students participation on the team $(15 \%$ of assignment grade), measured by:

i. The contributions the student made to the team discussion forum threads

ii. The ratings the student's teammates gave the student on the Collaboration Reflections

Figure 4: Evaluation Criteria

Although the ratings assigned by the student when using the Collaboration Reflection might be based on quantitative data, qualitative data, or a combination of both, it is vital that those ratings indeed be based on data and not on vague generalizations and impressions. Identifying meaningful data to support this peer- and self-evaluation is a great challenge. Ellis and Hafner (2005, 2006) tested and validated an instrument for developing these data by affording each team member the opportunity to rate the postings made by each of her or his teammates. Figure 5 displays the evaluation elements included in the instrument, with citations to the supporting literature sources for each element. Figure 6 illustrates the raw data that could be collected with a spreadsheet by reviewing each of the postings from the discussion forum transcripts of the team. Figure 7 presents an example of the information to support evaluation that can be derived from those data through aggregation and analysis, using the spreadsheet's PivotTable feature. 


\begin{tabular}{|c|c|}
\hline Evaluation Element & Scale Categories \\
\hline \multirow[t]{4}{*}{$\begin{array}{l}\text { Nature of contribution (Garrison, Anderson \& } \\
\text { Archer, 2000, 2001) }\end{array}$} & $\begin{aligned} \mathrm{Br}= & \text { Broadens discussion, a "brainstorming" } \\
& \text { type of contribution that adds new mate- } \\
& \text { rial to the topic being discussed. }\end{aligned}$ \\
\hline & $\begin{aligned} \mathrm{Fr}= & \text { Focuses discussion by building consensus } \\
& \text { and bringing the topic to a conclusion }\end{aligned}$ \\
\hline & $\begin{aligned} \mathrm{Re}= & \text { Reaffirms by expressing agreement and } \\
& \text { providing support for some other contri- } \\
& \text { bution }\end{aligned}$ \\
\hline & $\mathrm{Co}=$ Correcting mistakes \\
\hline \multirow{5}{*}{$\begin{array}{l}\text { Timeliness of contribution (Cazden \& Beck, } \\
\text { 2003) }\end{array}$} & $1=$ so late that it inhibited progress \\
\hline & $2=$ late enough to be an inconvenience \\
\hline & $3=$ made in a timely fashion \\
\hline & $\begin{array}{l}4=\text { made very promptly, exceeding expecta- } \\
\text { tions }\end{array}$ \\
\hline & $5=$ super-responsive \\
\hline \multirow{5}{*}{$\begin{array}{l}\text { Value of contribution (Jarvela \& Hakkinen, } \\
\text { 2003) }\end{array}$} & $1=$ really hurt progress \\
\hline & $2=$ distracting \\
\hline & $3=$ no real impact \\
\hline & $4=$ valuable \\
\hline & $5=$ essential \\
\hline \multicolumn{2}{|c|}{ Figure 5: Data Sources } \\
\hline
\end{tabular}

\begin{tabular}{|l|l|c|c|c|c|c|}
\hline Author & Subject & Date & Time & Nature & Timeliness & Value \\
\hline Ted W & e-mail correspondence & $12 / 11 / 02$ & $6: 40 \mathrm{PM}$ & $\mathrm{Fr}$ & 4 & 4 \\
\hline Kimberly F & here's a rough draft & $12 / 12 / 02$ & $5: 37 \mathrm{PM}$ & $\mathrm{Fr}$ & 4 & 4 \\
\hline Ted W & first draft & $12 / 12 / 02$ & $6: 05 \mathrm{PM}$ & $\mathrm{Re}$ & 4 & 4 \\
\hline Heidi K & Document & $12 / 12 / 02$ & $8: 59 \mathrm{PM}$ & $\mathrm{Re}$ & 4 & 4 \\
\hline Kimberly F & Heidi & $12 / 12 / 02$ & $10: 01 \mathrm{PM}$ & $\mathrm{Re}$ & 3 & 3 \\
\hline donna d & Requirements document & $12 / 13 / 02$ & $11: 06 \mathrm{AM}$ & $\mathrm{Re}$ & 3 & 3 \\
\hline Heidi K & Sample Document & $12 / 16 / 02$ & $11: 18 \mathrm{AM}$ & $\mathrm{Br}$ & 3 & 3 \\
\hline
\end{tabular}

Figure 6: Sample Raw Data 


\begin{tabular}{|l|l|r|r|r|r|}
\hline & & \multicolumn{4}{|c|}{ Nature of Posting } \\
\hline Author & & $\mathrm{Br}$ & $\mathrm{Co}$ & $\mathrm{Fr}$ & $\mathrm{Re}$ \\
\hline Donna D & Average Timeliness & & 2.00 & 3.00 & 3.00 \\
\hline & Average Value & & 3.00 & 4.00 & 3.00 \\
\hline & Count & & 1 & 2 & 1 \\
\hline Heidi K & Average Timeliness & 3.00 & 3.00 & 3.67 & 3.14 \\
\hline & Average Value & 3.00 & 3.00 & 4.33 & 3.29 \\
\hline & Count & 1 & 3 & 3 & 7 \\
\hline Kimberly F & Average Timeliness & 3.00 & 2.57 & 3.50 & 3.14 \\
\hline & Average Value & 4.00 & 2.57 & 3.50 & 3.14 \\
\hline & Count & 1 & 7 & 2 & 7 \\
\hline Ted W & Average Timeliness & 3.86 & 3.25 & 4.00 & 3.50 \\
\hline & Average Value & 4.43 & 3.75 & 4.00 & 3.50 \\
\hline & Count & 7 & 4 & 3 & 2 \\
\hline
\end{tabular}

This instrument did enable those students who chose to use it to produce meaningful peer- and self-evaluations of work as a member of a team (Ellis \& Hafner, 2006). Figure 8 presents samples of those evaluations, comparing two evaluations that were supported by data derived from this instrument with two unsupported evaluations. 


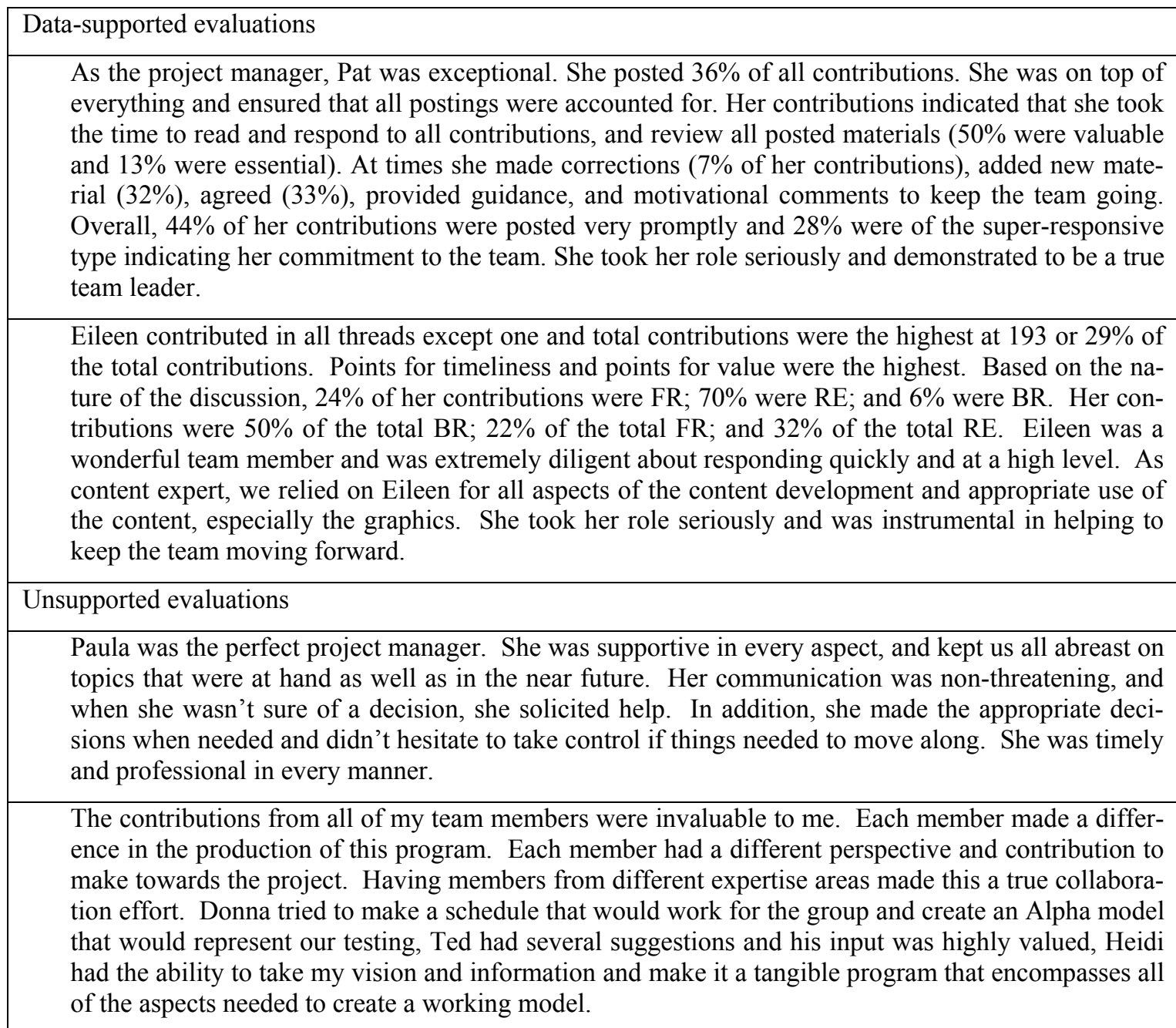

Figure 8: Assessment Samples

\section{Conclusions}

The goal of this study was to develop and test a model for planning project-based, team assignments for delivery via an asynchronous learning network. Three indicators of effectiveness were identified:

1. Facilitating the attainment of the learning outcome for which the assignment was designed.

2. Providing the instructor with a means to monitor and evaluate team-based assignments.

3. Alleviating student anxiety regarding team-based assignments.

As with so much in education, there are mixed results regarding the attainment of this goal. On the positive side, the results reported in a number of studies (Ellis \& Hafner, 2006, 2007; Hafner $\&$ Ellis, 2004) support the conclusion that the assignment as structured was effective in facilitating attainment of the identified learning outcomes and was viewed as a positive experience by the majority of the students, lending support to the first and third indicators. On the negative side those results suggest that the assignment was difficult for the instructor to monitor and evaluate 
and that for those students for whom the assignment "didn't work", the experience was markedly negative. In summary, indicator one appears to have been satisfied effectively by this projectbased, asynchronous collaborative learning model. Indicator three was at least partially satisfied, and indicator two does not appear to have been met.

As detailed in Hafner and Ellis (2004) and Ellis and Hafner (2006), student anxiety in PBCL assignments appears to be related to two factors: the perception of inadequate structure for the assignment, and discomfort with a totally asynchronous environment. This discomfort - especially that related to the structure - might well have been more directly associated with anxiety at having to function at a higher cognitive level. The learning outcomes that were to be facilitated by this assignment were cognitively demanding.

The difficulty in meeting the goal in terms of the second indicator - providing the instructor with a means to monitor and evaluate team-based assignments - appears to be a function of two factors. The instructor reported difficulty in effectively evaluating a part of the project documentation such as the project schedule in isolation. The instructor also indicated it was hard to accurately evaluate each individual's collaborative contributions without going into a detailed discourse analysis of the discussion forum.

This type of assignment presents a rather elevated risk-reward profile, illustrated in Figure 9. The benefits appear to be significant: students are able to work as members of a project team using primarily asynchronous tools for collaboration. True team interactions and processes do appear to grow during this activity and online students are afforded the opportunity of experiencing a learning environment that more closely parallels the reality of the workplace. The level of effort required by both the instructor and the student should not be

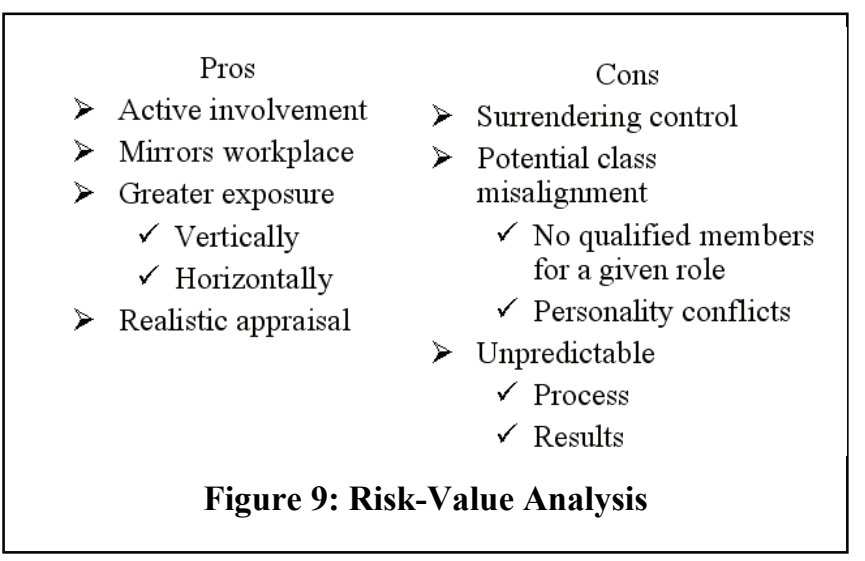

Figure 9: Risk-Value Analysis ignored, however. Assessment of the assignment is difficult and time consuming. Managing group-breakdowns such as withdrawals from the class and interpersonal conflicts can be quite challenging. Perhaps most significantly, the assignment presumes a level of sophistication and competence on the part of the students. The following observation by one of the less satisfied participants best illustrates this point: "At a graduate level the amount of structure should have been fine. In the case of my team it was insufficient." The impact of marginally qualified, socially inept, or distracted students is quite difficult to predict and manage.

\section{Implications for Future Studies}

The benefits associated with the task-based, team assignments certainly warrant further investigation into how to effectively integrate them into courses delivered via asynchronous learning networks. A number of topics for further research are suggested by the results of this study.

1. Our population was comprised of graduate students who were more 'mature' in project work and work experience in general than the traditional undergraduate or beginning graduate student. Examining the technique with that more traditional student population would be interesting.

2. How can the tools available in an asynchronous environment be utilized to alleviate the often frustrated desire for synchronous communication? 
3. How can instructors more effectively evaluate the participation of students in their role as a team member?

4. What is the proper balance between structure and freedom for teams to exercise initiative?

\section{References}

Allan, J., \& Street, M. (2007). The quest for deeper learning: An investigation into the impact of a knowledge-pooling WebQuest in primary initial teacher training. British Journal of Educational Technology, $38(6), 1102-1112$.

Beaudoin, M. F. (2002). Learning or lurking? Tracking the "invisible" online student. The Internet and Higher Education, 5(2), 147-155.

Benbunan-Fitch, \& Hiltz, R. (1998). Learning effects of asynchronous learning networks: A comparison of groups and individuals solving ethical case studies. Proceeding of HICSS-31. New York: IEEE.

Bloom, B. S. (1994). Reflections on the development and use of the taxonomy. Yearbook: National Society for the Study of Education, 92(2), 1-8.

Bloom, B. S., Engelhart, M. D., Furst, E. J., Hill, W. H., \& Krathwohl, D. R. (Eds.) (1956). Taxonomy of educational objectives, the classification of educational goals, Handbook I: Cognitive domain. New York: Longmans.

Brooks, C. M., \& Ammons, J. L. (2003). Free riding in group projects and the effects of timing, frequency, and specificity of criteria in peer assessments. Journal of Education for Business, 78(5), 268-272.

Cazden, C. B., \& Beck, S. W. (2003). Classroom discourse. In A.C. Graesser, M.A. Gernsbacker, \& S.R. Goldman (Eds.), Handbook of discourse processes (pp. 165-197). Mahwah, NJ: Lawrence Erlbaum Associates.

Collins-Eaglin, J., \& Karabenick, S. (1997). Relation of perceived instructional goals and incentives to college students' use of learning strategies, The Journal of Experimental Education, 65, 331-341.

Daggs, D., Styres, K., \& Turner, J. (1997). Encouraging mathematical thinking. Mathematics Teaching in the Middle School, 3, 66-72.

Dillenbourg, P., Baker, M., Blaye, A., \& O’Malley. (1996). Evolution of research on collaborative learning. In E. Spada \& P. Reiman (Eds.), Learning in humans and machine: Towards an interdisciplinary learning science (pp. 189-211). Oxford: Elsevier.R.M.

Ellis, T. J., \& Hafner, W. (2005). Peer evaluations of collaborative learning experiences conveyed through an asynchronous learning network. Proceedings of the 38th Hawaii International Conference on System Sciences. Piscataway, NJ: IEEE.

Ellis, T. J., \& Hafner, W. (2006). ACLE: A communication environment for asynchronous collaborative learning. Proceedings of the 39th Hawaii International Conference on System Sciences. Piscataway, NJ: IEEE.

Ellis, T. J., \& Hafner, W. (2007). Control structure in project-based asynchronous collaborative learning. Proceedings of the 40th Hawaii International Conference on System Sciences. Piscataway, NJ: IEEE.

Falchikov, N., \& Goldfinch, J. (2000). Student peer assessment in higher education: A meta-analysis comparing peer and teacher marks. Review of Educational Research, 70(3), 287-322.

Freeman, M., \& McKenzie, J. (2002). SPARK, A confidential web-based template for self and peer assessment of student teamwork: Benefits of evaluating across different subjects. British Journal of Educational Technology, 33(5), 551-569.

Fulford, C. P., \& Zhang, S. (1993). Perceptions of interaction: The critical predictor in distance education. The American Journal of Distance Education, 7(3), 8-21. 
Gagne, R. M., Briggs, L. J., \& Wagner, W.W. (1992). Principles of instructional design. New York: Harcourt Brace Jovanovich.

Garrison, D. R., Anderson, T., \& Archer, W. (2000). Critical inquiry in a text-based environment: Computer conferencing in higher education. The Internet and Higher Education, 2(2-3), 87-105.

Garrison, D. R., Anderson, T., \& Archer, W. (2001). Critical thinking, cognitive presence, and computer conferencing in distance education. The American Journal of Distance Education, 15(1), 7-23.

Goldfinch, J. (1994). Further developments in peer assessment of group projects. Assessment and Evaluation in Higher Education, 19(1), 29-35.

Guttman, H. M. (2004). Effective white-collar teams: The new quality imperative. Quality Progress, June(37), 6.

Hakkarainen, K., Muukonen, H., Lipponen, L., Ilomaki, L., Rahikainen, M., \& Lehtinen, E. (2001). Teachers' information and communication technology skills and practices of using ICT. Journal of Technology and Teacher Education, 9(2), 181-197.

Hafner, W., \& Ellis, T. J., (2004). Project-based, asynchronous collaborative learning. Proceedings of the 37th Hawaii International Conference on System Sciences. Piscataway, NJ: IEEE.

Henri, F. (1982). Computer conferencing and content analysis. In A. R. Kaye (Ed.), Collaborative learning through computer conferencing (pp. 117-136). Berlin: Springer-Verlag.

Herreid, C. (1998). Why isn't cooperative learning used to teach science? Bioscience, 48(7), 553-559.

Hill, J. R. (1999). Teaching technology: Implementing a problem-centered, activity-based approach, Journal of Research on Computing in Education, 31(3), 261-279.

Ikpeze, C. W., \& Boyd, F. B. (2007). Web-based inquiry learning: Facilitating thoughtful literacy with WebQuests. The Reading Teacher, 60(7), 644-654.

Jarvela, S., \& Hakkinen, P. (2003). The levels of web-based discussions: Using perspective-taking theory as an analytical tool. In H. v. Oostendorp (Ed.), Cognition in a digital world (pp. 77-95). Mahwah, NJ: Lawrence Erlbaum Associates.

Johnson, D. W., \& Johnson, R. T. (1996). Cooperation and the use of technology. In D. H. Jonassen, (Ed.), Handbook of research for educational communications and technology (pp. 1017-1044). New York: Simon and Schuster Macmillan.

Kanuka, H., Rourke, L., \& Laflamme, E. (2007). The influence of instructional methods on the quality of online discussion. British Journal of Educational Technology, 38(2), 206-271.

McCarthy, B. (1991). A tale of four learners: 4MAT's learning styles. Educational Leadership, 54(6), 4652.

McLoughlin, C., \& Luca, J. (2002). A learner-centered approach to developing skills through web-based learning and assessment. British Journal of Educational Technology, 33(5), 571-582.

Mezirow, J. (1991). Transformative DIMENSIONS OF ADULT LEARNING. San Francisco: Jossey-Bass.

Moore, M. G. (1989). Three types of interaction. The American Journal of Distance Education, 3(2), 1-6.

Morgan, R. L., Whorton, J. E., \& Gunsalus, C. (2000). A comparison of short-term and long-term retention: Lecture combined with discussion versus cooperative learning. Journal of Instructional Psychology, 27(1), 53-58.

Moursund, D. (2003). Project-based learning using information technology (2nd ed.). ISTE Publications.

Muir, S. P., \& Tracy, D. M. (1999). Collaborative essay testing just try it! College Teaching, 47(1), 33-35.

Niederhauser, D. S., Salem, D. J., \& Fields, M. (1999). Exploring teaching, learning, and instructional reform in an introductory technology course. Journal of Technology and Teacher Education, 7(2), 153172 . 
Orsburn, J. D., Moran, L., Musselwhite, E., \& Zenger, J. H. (1990). Self-directed work teams, the new American challenge. Irwin: Homewood, IL.

Riding, R., \& Grimley, M. (1999). Cognitive style, gender and learning from multimedia materials in 11year old children. British Journal of Educational Technology, 30(1), 43-56.

Roblyer, M. D., \& Wiencke, W. R. (2003). Design and use of a rubric to assess and encourage interactive qualities in distance education courses. The American Journal of Distance Education, 17(2), 77-98.

Romano, N. C., \& Nunamaker, J. F. (1998). A project-centered course: Collaborative computing. Proceedings of HICSS-31, New York: IEEE.

Schrire, S. (2003, Winter). A model for evaluating the process of learning in asynchronous computer conferencing. Journal of Instruction Delivery Systems, 17(1), 6-12.

Sloffer, S. J., Dueber, B., \& Duffy, T. M. (1999). Using asynchronous conferencing to promote critical thinking: Two implementations in higher education. Proceedings of HICSS-32. New York: IEEE.

Smock, C. D. (1981). Constructivism and educational practices. In I. E. Sigel, D. M. Brodzinski, \& R. M. Golinkoff (Eds.), New directions in Piagetian theory and practice (pp. 51-68). Hillsdale, NJ: Erlbaum.

Thomas, J. W. (2000). A review of research on project-based learning. San Rafael, CA: Autodesk Foundation.

Thompson, F, Baughan, D., \& Motwani, J. (1998). A case of innovative integration of high-performance work teams. Journal of Workplace Learning, 10(3), 157.

Van Duzer, E., \& McMartin, F. (2000). Methods to improve the validity and sensitivity of a self/peer assessment instrument. IEEE Transactions on Education, 43(2), 153-158.

Vaughan, T. (2004). Multimedia: Making it work (6th ed.). New York: McGraw-Hill.

Vygotsky, L. S. (1986). Language and thought. Cambridge, MA: MIT Press.

Walker, D. (2000). Process over product. The Technology Teacher, 59(4), 10-14.

Webb, N. M. (1997). Assessing students in small collaborative groups. Theory into Practice, 36(Autumn), 205-213.

Wentling, T. L., \& Johnson, S. D. (1999). The design and development of an evaluation system for online instruction. Web '99 World Conference on the WWW and Internet Proceedings (Honolulu, Hawaii, October 24-30, 1999), $2-7$.

Zimmerman, B. J. (1981). Social learning theory and cognitive constructivism. In I. E. Sigel, D. M. Brodzinski, \& R. M. Golinkoff (Eds.), New Directions in Piagetian Theory and Practice (pp 34-39). Hillsdale, NJ: Erlbaum. 


\section{Appendix: Collaboration Reflection}

In this reflection you will be responsible for evaluating the performance of each member of your team (including yourself). Please use the following scale for your evaluations:

\begin{tabular}{|c|l|}
\hline Rating & Definition \\
\hline 3 & Above Average Contribution to the Group \\
\hline 2 & Average Contribution to the Group \\
\hline 1 & Below Average Contribution to the Group \\
\hline 0 & No Contribution to the Group \\
\hline-1 & Hindrance to the Group \\
\hline
\end{tabular}

Be sure to support your ratings with data. Please note, your data might well be both quantitative and qualitative. Be sure to present and analyze each type of data in a manner consistent with reporting the results of scholarly research.

Please provide the following names for your team and its members.

\begin{tabular}{|l|l|}
\hline Team Name & \\
\hline Your Name & \\
\hline Teammate 1 & \\
\hline Teammate $\mathrm{n}$ & \\
\hline
\end{tabular}

\section{Collaboration (Check one box per item for each team member)}

Contribution: The group member contributed appropriate research to provide quality input to the group project.

\begin{tabular}{|l|l|l|l|l|l|}
\hline \multirow{2}{*}{ Team member } & \multicolumn{5}{|c|}{ Rating } \\
\cline { 2 - 6 } & 3 & 2 & 1 & 0 & -1 \\
\hline You & & & & & \\
\hline Teammate 1 & & & & & \\
\hline Teammate $\mathrm{n}$ & & & & & \\
\hline
\end{tabular}

Effort: The group member made an effort to identify areas where they could contribute to the project

\begin{tabular}{|l|l|l|l|l|l|}
\hline \multirow{2}{*}{ Team member } & \multicolumn{5}{|c|}{ Rating } \\
\cline { 2 - 6 } & 3 & 2 & 1 & 0 & -1 \\
\hline You & & & & & \\
\hline Teammate 1 & & & & & \\
\hline Teammate $\mathrm{n}$ & & & & & \\
\hline
\end{tabular}

Follow-through: The group member followed through with any commitments that were made.

\begin{tabular}{|l|l|}
\hline Team member & Rating \\
\hline
\end{tabular}




\begin{tabular}{|l|l|l|l|l|l|}
\hline & 3 & 2 & 1 & 0 & -1 \\
\hline You & & & & & \\
\hline Teammate 1 & & & & & \\
\hline Teammate $\mathrm{n}$ & & & & & \\
\hline
\end{tabular}

Response: The group member's responses reflected an analysis of the initial post.

\begin{tabular}{|l|l|l|l|l|l|}
\hline \multirow{2}{*}{ Team member } & \multicolumn{5}{|c|}{ Rating } \\
\cline { 2 - 7 } & 3 & 2 & 1 & 0 & -1 \\
\hline You & & & & & \\
\hline Teammate 1 & & & & & \\
\hline Teammate $\mathrm{n}$ & & & & & \\
\hline
\end{tabular}

Communication: The group member made good use of the communication channels selected by the group.

\begin{tabular}{|l|l|l|l|l|l|}
\hline \multirow{2}{*}{ Team member } & \multicolumn{5}{|c|}{ Rating } \\
\cline { 2 - 7 } & 3 & 2 & 1 & 0 & -1 \\
\hline You & & & & & \\
\hline Teammate 1 & & & & & \\
\hline Teammate $\mathrm{n}$ & & & & & \\
\hline
\end{tabular}




\section{Justification for Collaboration Ratings}

Provide a data-supported rationale for the ratings awarded each team member for her or his Contribution, Effort, Follow-through, Response, and Communication as a member of your team.

(There is no limit to the amount you can enter for each teammate)

You

Teammate 1

Teammate $n$

Participation (Check one box per item for each team member)

Time spent: The group member spent an adequate amount involved in group discussions.

\begin{tabular}{|l|l|l|l|l|l|}
\hline \multirow{2}{*}{ Team member } & \multicolumn{5}{|c|}{ Rating } \\
\cline { 2 - 6 } & 3 & 2 & 1 & 0 & -1 \\
\hline You & & & & & \\
\hline Teammate 1 & & & & & \\
\hline Teammate $\mathrm{n}$ & & & & & \\
\hline
\end{tabular}

Discussion: The group member contributed an adequate amount of contributions to the group discussions.

\begin{tabular}{|l|l|l|l|l|l|}
\hline \multirow{2}{*}{ Team member } & \multicolumn{5}{|c|}{ Rating } \\
\cline { 2 - 6 } & 3 & 2 & 1 & 0 & -1 \\
\hline You & & & & & \\
\hline Teammate 1 & & & & & \\
\hline Teammate $\mathrm{n}$ & & & & & \\
\hline
\end{tabular}

Quality: The group member's contributions were of good quality.

\begin{tabular}{|l|l|l|l|l|l|}
\hline \multirow{2}{*}{ Team member } & \multicolumn{5}{|c|}{ Rating } \\
\cline { 2 - 7 } & 3 & 2 & 1 & 0 & -1 \\
\hline You & & & & & \\
\hline Teammate 1 & & & & & \\
\hline Teammate $\mathrm{n}$ & & & & & \\
\hline
\end{tabular}


Response: The group member responded to questions posted by other members of the group.

\begin{tabular}{|l|l|l|l|l|l|}
\hline \multirow{2}{*}{ Team member } & \multicolumn{5}{|c|}{ Rating } \\
\cline { 2 - 6 } & 3 & 2 & 1 & 0 & -1 \\
\hline You & & & & & \\
\hline Teammate 1 & & & & & \\
\hline Teammate $\mathrm{n}$ & & & & & \\
\hline
\end{tabular}

Contribution: The group member's contributions increase the group's learning.

\begin{tabular}{|l|l|l|l|l|l|}
\hline \multirow{2}{*}{ Team member } & \multicolumn{5}{|c|}{ Rating } \\
\cline { 2 - 6 } & 3 & 2 & 1 & 0 & -1 \\
\hline You & & & & & \\
\hline Teammate 1 & & & & & \\
\hline Teammate $\mathrm{n}$ & & & & & \\
\hline
\end{tabular}

Compliment: The group member expanded on points posted by other members.

\begin{tabular}{|l|l|l|l|l|l|}
\hline \multirow{2}{*}{ Team member } & \multicolumn{5}{|c|}{ Rating } \\
\cline { 2 - 6 } & 3 & 2 & 1 & 0 & -1 \\
\hline You & & & & & \\
\hline Teammate 1 & & & & & \\
\hline Teammate $\mathrm{n}$ & & & & & \\
\hline
\end{tabular}

Originality: The group member introduced new information to the group.

\begin{tabular}{|l|l|l|l|l|l|}
\hline \multirow{2}{*}{ Team member } & \multicolumn{5}{|c|}{ Rating } \\
\cline { 2 - 7 } & 3 & 2 & 1 & 0 & -1 \\
\hline You & & & & & \\
\hline Teammate 1 & & & & & \\
\hline Teammate $\mathrm{n}$ & & & & & \\
\hline
\end{tabular}




\section{Justification for Participation Ratings}

Provide a data-supported rationale for the ratings awarded each team member for her or his Time spent, Discussion, Quality, Response, Contribution, Compliment, and Originality as a member of your team. (There is no limit to the amount you can enter for each teammate)

You

Teammate 1

\section{Cooperation (Check one box per item for each team member)}

Compromise: The group member was open to compromise on key issues to move the project forward.

\begin{tabular}{|l|l|l|l|l|l|}
\hline \multirow{2}{*}{ Team member } & \multicolumn{5}{|c|}{ Rating } \\
\cline { 2 - 7 } & 3 & 2 & 1 & 0 & -1 \\
\hline You & & & & & \\
\hline Teammate 1 & & & & & \\
\hline Teammate $\mathrm{n}$ & & & & & \\
\hline
\end{tabular}

Timeliness: The group member was timely in fulfilling any commitments.

\begin{tabular}{|l|l|l|l|l|l|}
\hline \multirow{2}{*}{ Team member } & \multicolumn{5}{|c|}{ Rating } \\
\cline { 2 - 6 } & 3 & 2 & 1 & 0 & -1 \\
\hline You & & & & & \\
\hline Teammate 1 & & & & & \\
\hline Teammate $\mathrm{n}$ & & & & & \\
\hline
\end{tabular}

Professionalism: The group member discussed in a professional manner within the group.

\begin{tabular}{|l|l|l|l|l|l|}
\hline \multirow{2}{*}{ Team member } & \multicolumn{5}{|c|}{ Rating } \\
\cline { 2 - 6 } & 3 & 2 & 1 & 0 & -1 \\
\hline You & & & & & \\
\hline Teammate 1 & & & & & \\
\hline Teammate $\mathrm{n}$ & & & & & \\
\hline
\end{tabular}


Initiative: The group member took the initiative to contact other group members and maintain effective communication patterns.

\begin{tabular}{|l|l|l|l|l|l|}
\hline \multirow{2}{*}{ Team member } & \multicolumn{5}{|c|}{ Rating } \\
\cline { 2 - 6 } & 3 & 2 & 1 & 0 & -1 \\
\hline You & & & & & \\
\hline Teammate 1 & & & & & \\
\hline Teammate $\mathrm{n}$ & & & & & \\
\hline
\end{tabular}

Commitment: The group member stayed on task.

\begin{tabular}{|l|l|l|l|l|l|}
\hline \multirow{2}{*}{ Team member } & \multicolumn{5}{|c|}{ Rating } \\
\cline { 2 - 6 } & 3 & 2 & 1 & 0 & -1 \\
\hline You & & & & & \\
\hline Teammate 1 & & & & & \\
\hline Teammate $\mathrm{n}$ & & & & & \\
\hline
\end{tabular}

Fairness: The group member's contributions met expectations regarding division of labor.

\begin{tabular}{|l|l|l|l|l|l|}
\hline \multirow{2}{*}{ Team member } & \multicolumn{5}{|c|}{ Rating } \\
\cline { 2 - 6 } & 3 & 2 & 1 & 0 & -1 \\
\hline You & & & & & \\
\hline Teammate 1 & & & & & \\
\hline Teammate $\mathrm{n}$ & & & & & \\
\hline
\end{tabular}

\section{Justification for Cooperation Ratings}

Provide a data-supported rationale for the ratings awarded each team member for her or his Compromise, Timeliness, Professionalism, Initiative, Commitment, and Fairness as a member of your team. (There is no limit to the amount you can enter for each teammate)

You

Teammate 1

Teammate $\mathrm{n}$ 


\section{Biographies}

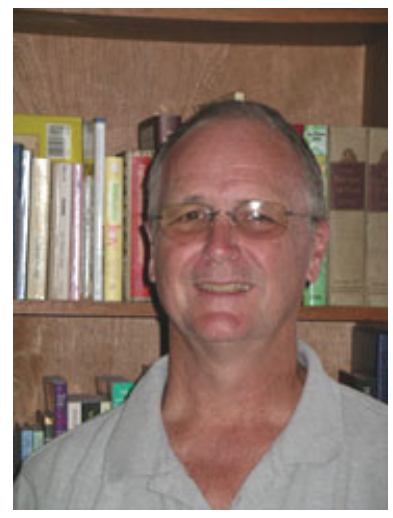

Dr. Timothy Ellis obtained a B.S. degree in History from Bradley University, an M.A. in Rehabilitation Counseling from Southern Illinois University, a C.A.G.S. in Rehabilitation Administration from Northeastern University, and a Ph.D. in Computing Technology in Education from Nova Southeastern University. He joined NSU as Assistant Professor in 1999 and currently teaches computer technology courses at both the Masters and Ph.D. level in the School of Computer and Information Sciences. Prior to joining NSU, he was on the faculty at Fisher College in the Computer Technology department and, prior to that, was a Systems Engineer for Tandy Business Products. His research interests include: multimedia, distance education, and adult learning. He has published in several technical and educational journals including Catalyst, Journal of Instructional Delivery Systems, and Journal of Instructional Multimedia and Hypermedia. His email address is ellist@,nova.edu. His main website is located at http://www.scis.nova.edu/ ellist/

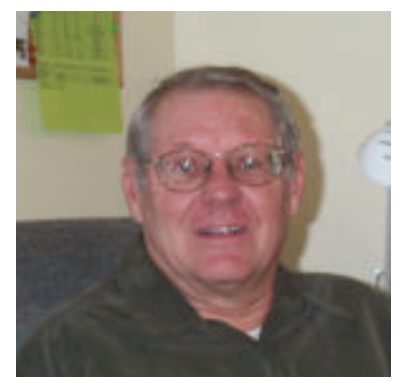

Dr. William Hafner possesses a long career in industrial software development and management. He has had senior positions for major computer and telecommunications companies and was a research scientist for the Department of Energy. He led the developed large-scale applications in databases, telecommunications, engineering and mathematical processing. Dr. Hafner's research interests are in the areas of privacy and security. He is especially interested in privacy and its impact on IT, privacy representation languages, data governance, and federated identity management. Dr. Hafner is an Associate Professor in the Graduate School of Computer and Information Sciences and Director of the Institute for Privacy and Security Studies (IPASS) at Nova Southeastern University in Ft. Lauderdale, FL. 